\title{
Treatment of conjunctival squamous cell carcinoma with topical 5-fluorouracil
} Edoardo Midena, Claudia Degli Angeli, Massimo Valenti, Valentina de Belvis,
Paolo Boccato local excision and supplemental cryotherapy, with accurate histological assessment of surgical margins. ${ }^{2}$ However, the recurrence rate is still high, even when surgical margins of primary excision are free from malignant cells. ${ }^{3}$ Moreover, recurrences may be multiple and their occurrence greatly increases the risk of local spread. ${ }^{4}$ Local irradiation is sometimes used in conjunction with repeated excision to treat conjunctival recurrences of squamous cell carcinoma ${ }^{5}$; however, side effects limit the use of supplemental irradiation.

Topical conjunctival chemotherapy with antineoplastic drugs has recently been proposed as a new approach in the treatment of conjunctival premalignant lesions (primary acquired melanosis and conjunctival intraepithelial neoplasia) with promising results. ${ }^{7-16} \mathrm{~A}$ few years ago, after some anecdotal observations, we started a prospective non-randomised study to evaluate the efficacy of topical 5-fluorouracil (5-FU) in the treatment of recurrent, partially excised, and selected untreated (see below) conjunctival squamous cell carcinomas.

We report clinical and morphological findings seen in our patients affected by conjunctival squamous cell carcinoma treated with topical $1 \% 5-F U$.

\section{Patients and methods}

Eight patients with conjunctival squamous cell carcinoma (CSCC) were treated with topical 5-FU (Fluoro-Uracile Roche, Roche spa, Milan, Italy) alone (Table 1). A consent statement, approved by the ethics committee, was signed by each patient. Antineoplastic eye drops were prepared by our laboratory and each patient received a new bottle of eye drops weekly during the treatment course.

All patients were examined by the senior author (EM) and were included in this study after complete eye examination and review of histopathological and/or cytological findings. Baseline histopathological specimens were available for all patients, except two who had refused surgery as a primary procedure. In these last two cases diagnosis was made examining multiple cytological smears of the affected conjunctiva. All patients underwent baseline clinical examination and photography. 5 -FU $1 \%$ eye drops were prepared in aqueous solution and then administered four times daily during the course of 4 weeks. Clinical examination was performed weekly during the treatment and then after 15 days, 1,3 , and 6 months. Morphological follow up (1, 3, and 6 months after therapy) of all cases was performed using cytological smears, which were 

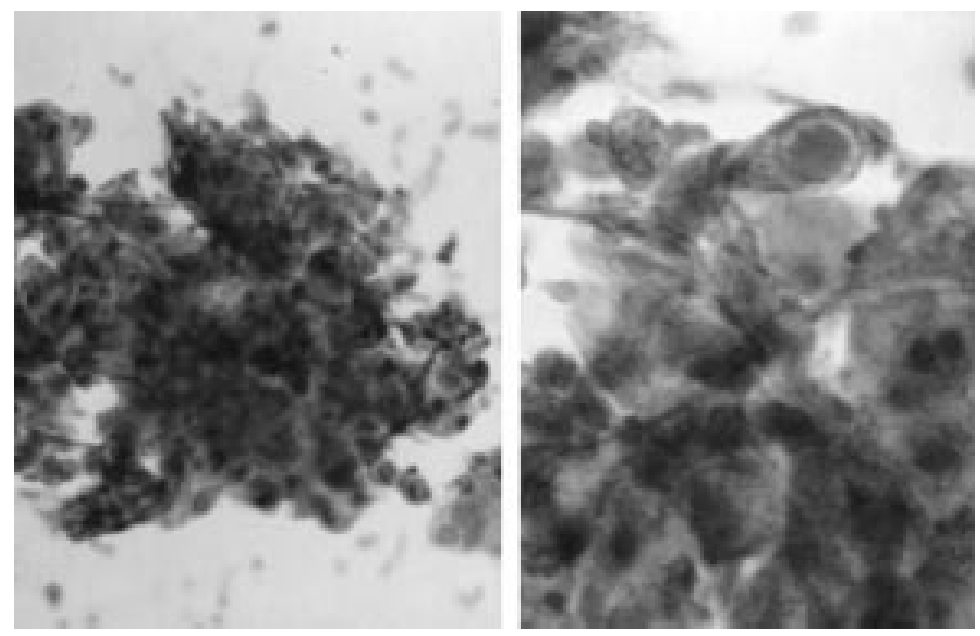

Figure 1 Conjunctival cytological smears of a case of recurrent squamous cell carcinoma: the picture is consistent with moderately differentiated squamous cell carcinoma (Papanicolaou, original magnification $\times 125$ (left) and $\times 240$ (right)).
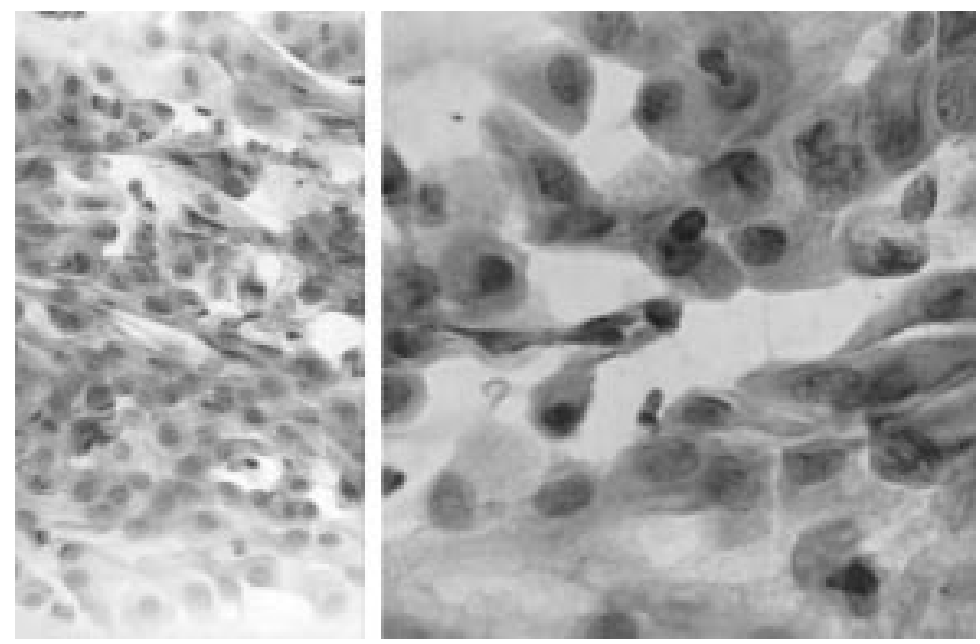

Figure 2 Conjunctival cytological smears obtained 3 months after the end of one course of 5- fluorouracil (in the same patient and conjunctival area of Fig 1) show normal conjunctival epithelial cells (Papanicolaou, original magnification $\times 125$ (left) and $\times 240$ (right)).
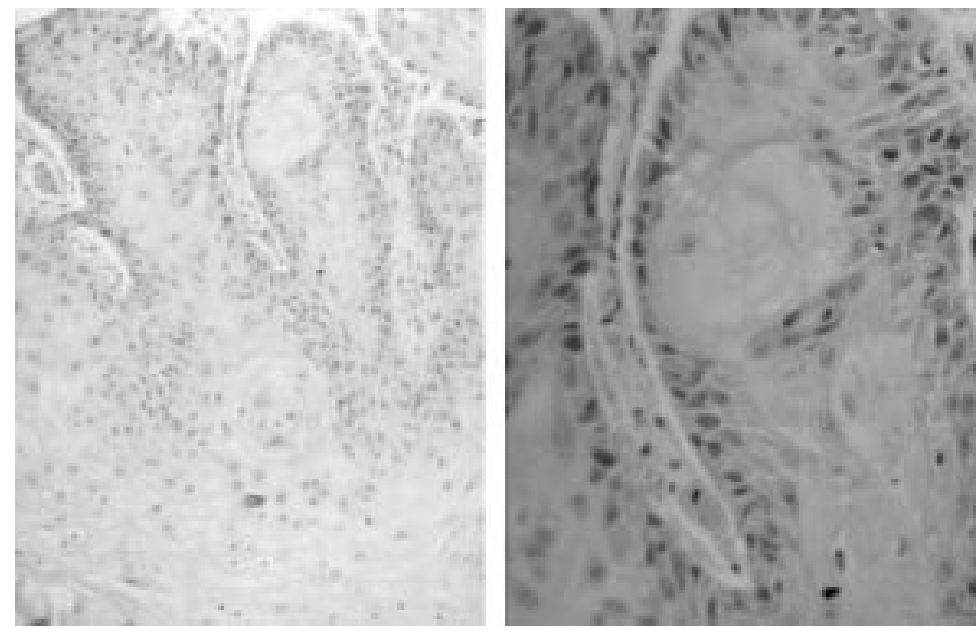

Figure 3 Histopathological specimens of a conjunctival biopsy in a case of recurrent squamous cell carcinoma (haematoxylin and eosin, original magnification $\times 180$ (left) and $\times 240$ (right)).

obtained with the scraping technique. The sampling procedure was always performed by the senior author (EM) in the following manner: the area to be sampled was vigorously scraped and four or five specimens were collected from each lesion. We have previously shown ${ }^{16}$ that this technique allows adequate sampling of superficial and deep conjunctival cells. All patients were then followed at 6 month intervals for any evidence of clinical or morphological recurrence. At the last follow up examination a conjunctival biopsy was performed at the site of the original lesions, except for the two patients who had refused primary surgery.

Patients were instructed about local side effects. After instillation of the eye drops the inferior lacrimal punctum was briefly occluded and an eye ointment was applied on the inferior eyelid skin to minimise skin contact with the antineoplastic drug.

\section{Results}

All patients involved in this study had a minimum follow up of 13 months (range 13-53 months; mean 27 months). No patient was lost to follow up.

The patients had a mean age of 70 years (range 57-91 years); six were male and two were female. Three patients had incompletely excised primary CSCC, three patients had local recurrence of CSCC, and two patients had untreated CSCC. The mean largest diameter of the lesions (excluding the diffuse case: case 2, Table 1 ) was $5.6 \mathrm{~mm}$ (range $1-12 \mathrm{~mm}$ ).

Local excision was not performed as a primary procedure in two cases for the following reasons: one patient was elderly (that is, 91 years old) and affected by a diffuse CSCC which was not amenable to treatment without transplantation of normal conjunctiva from the fellow eye (this case has been previously reported in detail). ${ }^{16}$ The second patient had CSCC in his only seeing eye and had refused surgery proposed elsewhere. In these two cases baseline diagnosis was performed on cytological smears according to standard cytological criteria of malignancy: cell atypia, loss of polarity, unfavourable nuclear/cytoplasmic ratio, dirty (necrotic) background. All other cases had histological documentation of their lesion.

The interval between the primary incomplete excision (three patients) and topical chemotherapy was 4-6 weeks. The mean interval between the primary complete excision of CSCC (three patients) and local recurrence was 22 months. All patients completed the entire course of 4 weeks of local chemotherapy. Transient conjunctivitis and superficial keratitis were observed in all patients during the third or fourth week of treatment. This side effect was easily controlled with topical drugs (artificial tears and antibiotics) in 5-6 days. Seven patients had complete and stable regression of their conjunctival lesions. One patient (case 3, Table 1) had a clinical local recurrence, in a previously involved area, 6 months after topical chemotherapy. $\mathrm{He}$ was successfully retreated with a new 4 week course of 5-FU without major side effects. After 19 months of follow up he remains disease free. Four patients $(50 \%)$ had concomitant conjunctival and corneal involvement, both of which regressed with treatment. At the 3 


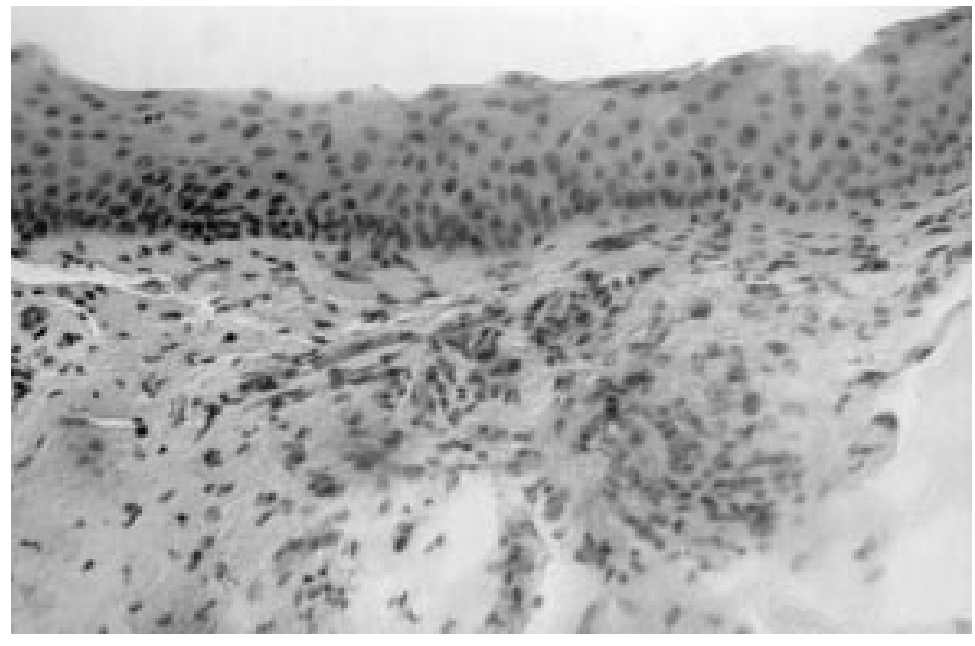

Figure 4 Histopathological specimen of the case shown in Figure 3, 23 months after the end of 5-fluorouracil topical treatment. Normal conjunctiva has replaced the carcinomatous area (haematoxylin and eosin, original magnification $\times 125$ ).

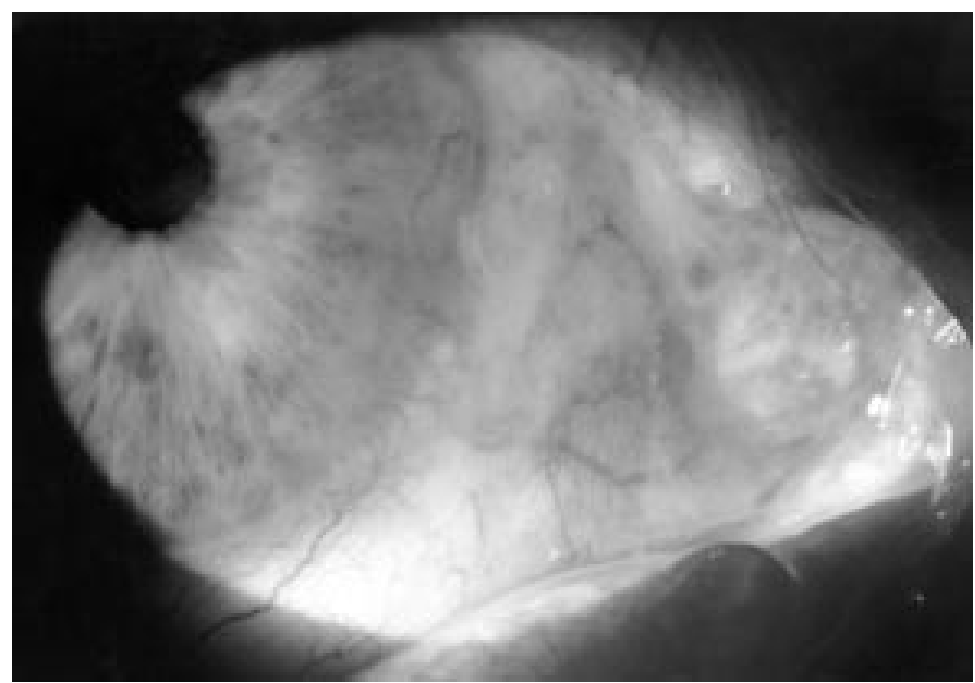

Figure 5 Clinical picture of a diffuse conjunctival squamous cell carcinoma (case 2; Table 1) before treatment with topical $1 \%$ 5-fluorouracil.

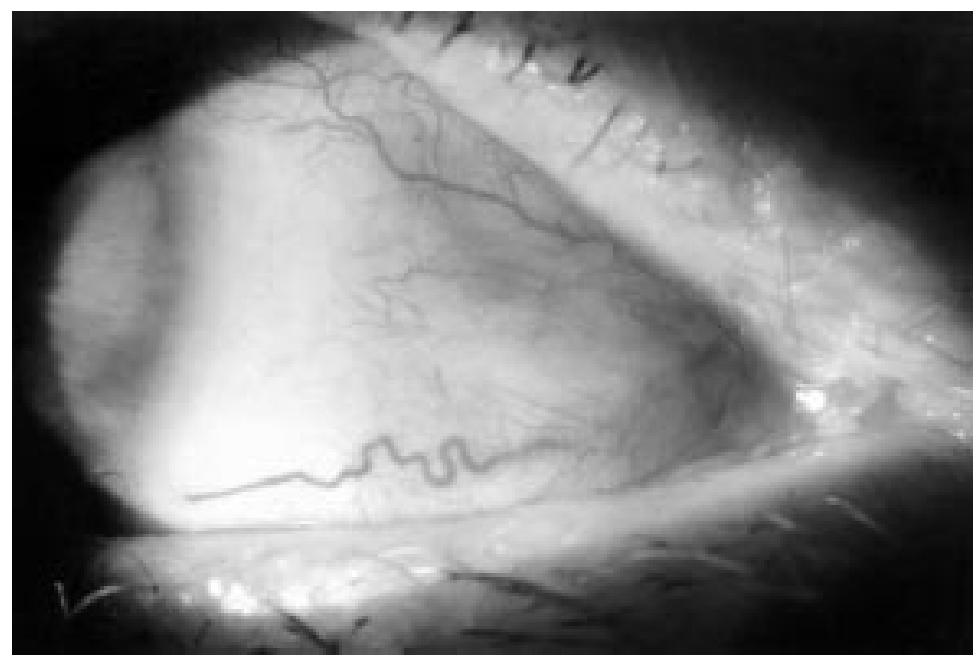

Figure 6 The conjunctiva in the same area as shown in Figure 5, 3 months after the end of treatment with 5-fluorouracil. No clinical signs of the lesion are present.

month examination cytological specimens from the areas previously containing malignant cells showed only normal conjunctival epithelial and goblet cells (Figs 1 and 2).
No malignant cells were subsequently found, except for the recurrent case, by thorough examination of conjunctival cytological smears. Conjunctival biopsy performed during last clinical examination confirmed the cytological results (Figs 3 and 4). Figures 5 and 6 show one successfully treated case (case 2) before and after local chemotherapy.

\section{Discussion}

Eight patients affected by CSCC (three recurrent cases, three incompletely excised, and two previously untreated cases) were treated with topical 5-FU alone with remission of the disease after one or more courses of local chemotherapy.

The finding that surgical excision, alone or combined with cryotherapy, is sometimes not sufficient to eradicate conjunctival malignant tumours has been recently emphasised by Shields et al, who propose a systematic and radical surgical approach to these tumours. ${ }^{2}$ One of the major limitations of surgery alone is that margins which appear clinically free of disease at the time of surgery may, on later pathological examination, demonstrate infiltration by malignant cells. Moreover, the presence of free margins, both by clinical and pathological evaluation, does not guarantee that a conjunctival malignant tumour is completely eradicated, as reported by Erie et al for squamous tumours. ${ }^{3}$ These authors found that $40 \%$ of patients with invasive squamous cell carcinoma and $5 \%$ of patients with conjunctival intraepithelial neoplasm had local recurrence even if they had free surgical margins after primary excision. These figures increased to $100 \%$ and $53 \%$ respectively when the surgical margins were invaded by neoplasia. When neoplastic cells are identified at the margins of resection of a conjunctival carcinoma a wide resection of the surgical scar with adjuvant cryotherapy is indicated. The use of radiotherapy is of limited value in the treatment of recurrent squamous carcinoma of the conjunctiva because radiotherapy can give rise to ocular side effects ${ }^{56}$ and because the beneficial effects of radiotherapy are necessarily limited to the treated areas. Therefore, a treatment modality selective for neoplastic cells, wherever located in the entire conjunctiva, may represent an effective approach for the treatment of recurrent CSCC and some selected cases of untreated tumours - diffuse and poorly demarcated tumours, patients refusing surgery, or in poor health.

$5-\mathrm{FU}$ is currently used to inhibit the proliferation of subconjunctival fibroblasts after filtration surgery. There are only a few reports of its use as an antineoplastic drug for the treatment of ocular surface neoplasia. ${ }^{81316}$ In 1986, de Keizer et al successfully treated with 5 -FU eye drops ( $1 \%)$ two of three patients affected by carcinoma in situ of the conjunctiva and cornea. ${ }^{13}$ Topical 5 -FU $1 \%$ was also used by Yeatts et al to treat three cases of carcinoma in situ, one case of invasive carcinoma, and two cases of conjunctival dysplasia. ${ }^{8}$ Surgical excision was used before topical chemotherapy in five of six cases. One patient treated for 
conjunctival dysplasia with 5-FU alone was disease free at the last follow up. Among the remaining five patients, three were disease free at the last examination. The efficacy of topical chemotherapy was clinically assessed in all patients, but morphologically documented in one patient. These authors used 5-FU four times daily for 14-21 days for a total of three periods. 5-FU was always discontinued when epithelial separation was obtained. No long term side effects were found.

Our study differs in some respects from previous reports. All patients were prospectively followed according to a standardised protocol with clinical and morphological examination, which continues after topical chemotherapy at 6 month intervals. This agrees with the guidelines recently suggested by Grossniklaus and Aaberg for antineoplastic topical chemotherapy. ${ }^{15}$ This methodology allowed us to monitor the relatively long term effect (more than 17 months in six of eight patients, and more than 2 years in four of eight cases) of 5 -FU chemotherapy in eradicating recurrent or primary CSCC. Our results were not influenced by concomitant radical surgery or repeated biopsies which may be a confounding factor, as reported by Frucht-Pery et al..$^{10}$ Thus our data show the effect of 5-FU alone. Moreover, all our patients had (untreated or recurrent) malignant tumours, because our aim was to evaluate the efficacy of topical chemotherapy for the treatment of malignant CSCC. Our decision to use 5-FU instead of mitomycin $\mathrm{C}$, as recently proposed by other authors, was based on pharmacological and biological data. ${ }^{1314} 17$ 5-FU is a pyrimidine analogue commonly used to treat many epithelial cancers. It acts by interacting with $S$ phase cells (those actively synthesising DNA). ${ }^{17}$ Therefore, it is suitable to treat squamous cell carcinoma because squamous tumours are composed of rapidly proliferating abnormal epithelial cells. ${ }^{13}$ It has limited side effects on the normal surface epithelium, as demonstrated by our results. 5-FU is an inexpensive drug, easily handled by medical personnel and patients, and is stable in aqueous solution for at least 3 weeks (Midena and Fregona, unpublished data). It does not need to be stored in a refrigerator, as does mitomycin C. On the other hand, mitomycin $\mathrm{C}$ is relatively unstable in solution and its action decreases in 8-10 days (Midena and Fregona, unpublished data). The acute and chronic side effects of mitomycin $\mathrm{C}$ are definitely much more frequent and serious than those induced by $5-\mathrm{FU}$, as referred to by clinicians using mitomycin $\mathrm{C}$ for pigmented conjunctival lesions ( $M$ Jager and MA Blasi, personal communications, 1999). Caution is advised in patients with conditions that predispose to epithelial dysfunction. ${ }^{10}$

The present study has some limitations. Firstly, the dosage of 5-FU was arbitrarily chosen after reviewing scanty literature data. ${ }^{8131617}$ Perhaps the 5-FU concentration can be increased to satisfy the general chemotherapy principle that each drug should be used at the highest tolerated dose. ${ }^{17}$ But no data exist in ophthalmic clinical practice about the safety of higher 5-FU dosage. Secondly, our mean follow up was 27 months. A longer follow up time is necessary to confirm the long term efficacy of our treatment modality with respect to local tumour control.

We have used cytological specimens to monitor the morphological effects of our treatment on conjunctival lesions. Contrasting data and different opinions exist about the use of cytological smears to diagnose conjunctival malignancies. ${ }^{18-23}$ Glasgow and Foos questioned the use of cytological smears for grading conjunctival dysplasia. ${ }^{18}$ But Gelender and Forster, ${ }^{19}$ Paridaens et $a l,{ }^{20}$ and $\mathrm{Naib}^{21}$ have used this method with satisfactory results. We have used cytological specimens for the past 15 years to obtain valuable information regarding premalignant and malignant lesions of the conjunctiva. ${ }^{24}{ }^{25}$ Moreover, the cytological collection obtained with the scraping technique we described is well accepted by the patient and may be repeated as many times as necessary without inducing morphological alterations in the sampled area. We agree that histopathology is superior to cytology to define the type and depth of invasion of any conjunctival neoplastic lesion, but we are not convinced that conjunctival biopsy is the best method to sequentially sample small conjunctival areas without becoming an excisional surgical modality itself. This method may limit the possibility of monitoring correctly the sequence of events induced by 5-FU chemotherapy on conjunctival neoplastic areas. ${ }^{10}$ In any case, six of the eight patients underwent a final surgical biopsy, which confirmed the cytological results.

This was a prospective but not a randomised study. The aim of this study was merely to test the efficacy of topical 5-FU for the treatment of CSCC in clinical situations where an alternative to surgery or adjunctive treatment is required.

This pilot study does not advocate that topical 5-FU should be used routinely in the treatment of conjunctival squamous cell carcinoma, but it shows that topical chemotherapy with 5-FU alone was effective in eradicating CSCC in our patients, without major and/or long term side effects. Therefore, the use of topical 5-FU should be more widely investigated, in prospective randomised trials, to define its role in the treatment of recurrent or selected untreated CSCC.

1 McLean IW, Burnier MN, Zimmerman LE, et al. Tumors of the eye and ocular adnexa. 3rd series fascicle 12. Washington, DC:Armed Forces Institute of Pathology, 1994:50-2. 2 Shields JA, Shields CL, De Potter P. Surgical management of conjunctival tumors. Arch Ophthalmol 1997;115:808-15. 3 Erie JC, Campbell RJ, Liesegang TJ. Conjunctival and corneal intraepithelial and invasive neoplasia. Ophthalmology 1986;93:176-83.

4 Tabin G, Levin S, Snibson G, et al. Late recurrences and the necessity for long-term follow-up in corneal and conjunctival intraepithelial neoplasia. Ophthalmology 1997;104:48592.

5 Lommatzsch PK. Beta-ray treatment of malignant epithelial tumors of the conjunctiva. Am f Ophthalmol 1976;41:198206.

6 Lommatzsch PK. Conjunctival tumors and their radiotherapy. In: Alberti WE, Sagerman RH, eds. Radiotherapy of intraocular and orbital tumors. Berlin: Springer-Verlag, 1993; intraocular chapter 25.
chat

7 Frucht-Pery J, Rozenman Y. Mitomycin C therapy for corneal intraepithelial neoplasia. Am $\mathcal{F}$ Ophthalmol 1994; 117:164-8. 
8 Yeatts RP, Ford JC, Stanton CA, et al. Topical 5-fluorouracil in treating epithelial neoplasia of the conjunctiva and 1995;102:1338-44.

9 Frucht-Pery J, Pe'er J. Use of mitomycin C in the treatment of conjunctival primary acquired melanosis with atypia Arch Ophthalmol 1996;114:1261-4.

10 Frucht-Pery J, Sugar J, Baum J, et al. Mitomycin C treatment for conjunctival-corneal intraepithelial neoplasia: multicenter experience. Ophthalmology 1997; 104:2085-93

11 Wilson MA, Hungerford JL, George SM, et al. Topical mitomycin $\mathrm{C}$ for the treatment of conjunctival and corneal epithelial dysplasia and neoplasia. Am $\mathcal{f}$ Ophthalmol 1997;124:303-11.

12 Heigle TJ, Stulting RD, Palay DA. Treatment of recurrent conjunctival epithelial neoplasia with topical mitomycin C. Am f Ophthalmol 1997;124:397-9.

13 De Keizer RJW, De Wolff-Rouendaal D, Van Delft JL. Topical application of 5-fluorouracil in premalignant lesions of cornea, conjunctiva and eyelid. Doc Ophthalmol 1986;64: cornea,

14 Finger PT, Milner MS, McCormick SA. Topical chemotherapy for conjunctival melanoma. Br F Ophthalmol 1993; $77: 751-53$

15 Grossniklaus HE, Aaberg TM sr. Mitomycin C treatment of conjunctival intraepithelial neoplasia. (Editorial) $A m \mathcal{F}$ Ophthalmol 1997;124:381-3.

16 Midena E, Degli Angeli C, Boccato P. Conjunctival squamous cell carcinoma treated with topical fluorouracil Arch Ophthalmol 1997;115:1600-1.
17 Hardman JG, Goodman Gilman A, Limbird LE. In: Goodman and Gilman's the pharmacological basis of therapeutics. 9th ed. New York: McGraw-Hill, 1996:1225-87.

18 Glasgow BJ, Foos RY. Ocular cytopathology. Boston: Butterworth-Heinemann, 1993:26-8

19 Gelender H, Forster RK. Papanicolaou cytology in the diagnosis and management of external ocular tumors. Arch Ophthalmol 1980;98:909-12.

20 Paridaens ADA, McCartney ACE, Curling OM, et al. Impression cytology of conjunctival melanosis and melanoma. Br f Ophthalmol 1992;76:198-201.

21 Naib ZM. Cytopathology. Boston: Little Brown, 1996:54950

22 Hirst LW, Bancroft BJ, Nolan GR, et al. Ocular surface squamous neoplasia identified by impression cytology in clinically normal eyes: low specificity or true dysplasia? (ARVO Abstracts) Invest Ophthalmol Vis Sci 1998;39:S542. (ARVO Abstracts) I

23 Nolan GR, Hirst LW, Bancroft BJ. Impression cytology in identification of ocular surface squamous neoplasia: is it accurate? (ARVO Abstracts) Invest Ophthalmol Vis Sci 1998;39:S543. (Abstract no 2500.)

24 Midena E, Segato T, Blarzino MC. Effects of ionizing radiation on human conjunctival epithelial cells: a clinical and cytologic study. Ophthalmologica 1991;203:75-81.

25 Boccato P, Blandamura S, Midena E. Citodiagnostica in ftalmologia. Rome: Edizioni Medico Scientifiche Internazionali, 1994:169-92. 